\title{
Alain Legros, Montaigne et Gournay en marge des "Essais": trois petites notes pour quatre mains
}

\section{Filippo Fonio}

\section{(2) OpenEdition}

1 Journals

\section{Edizione digitale}

URL: http://journals.openedition.org/studifrancesi/35951

DOI: 10.4000/studifrancesi.35951

ISSN: 2421-5856

\section{Editore}

Rosenberg \& Sellier

\section{Edizione cartacea}

Data di pubblicazione: 1 juillet 2005

Paginazione: 150

ISSN: 0039-2944

\section{Notizia bibliografica digitale}

Filippo Fonio, "Alain Legros, Montaigne et Gournay en marge des "Essais": trois petites notes pour quatre mains», Studi Francesi [Online], 145 (XLIX | I) | 2005, online dal 30 novembre 2015, consultato il 18 avril 2021. URL: http://journals.openedition.org/studifrancesi/35951 ; DOI: https://doi.org/10.4000/ studifrancesi.35951

Questo documento è stato generato automaticamente il 18 avril 2021.

\section{(c)}

Studi Francesi è distribuita con Licenza Creative Commons Attribuzione - Non commerciale - Non opere derivate 4.0 Internazionale. 


\title{
Alain Legros, Montaigne et Gournay en marge des "Essais": trois petites notes pour quatre mains
}

\author{
Filippo Fonio
}

\section{NOTIZIA}

ALAIN LEGROS, Montaigne et Gournay en marge des "Essais": trois petites notes pour quatre mains, «Bibliothèque d'Humanisme et Renaissance», LXV, 3 (2003), pp. 613-630.

$1 \quad$ Il presente contributo rappresenta un tassello nella storia della genesi degli Essais e dei rimaneggiamenti che l'opera subisce dalla prima edizione alla morte di Montaigne. Fra il giugno e il novembre 1588 Montaigne, convalescente, soggiorna in Picardie ospite di Marie de Gournay, sua "segretaria occasionale" la cui collaborazione può essere riscontrata in alcune aggiunte che compariranno nella nuova edizione degli Essais, stampata a Bordeaux nel 1588. L'analisi paleografica compiuta da Legros intende restituire la mano di Montaigne e quella della collaboratrice (che spesso si alternano in un lavoro che procede per accumulazione) alle aggiunte e correzioni risalenti al periodo del soggiorno presso Marie de Gournay. Lo studioso mostra inoltre come i testi composti in questo frangente risentano in misura non secondaria della turbolenta situazione politica, che vede lo strapotere di Henri de Guise, entrato ormai a Parigi nei giorni che precedono il suo assassinio. 